\title{
Fluid flow analysis of drooping phenomena in pump mode for a given guide vane setting of a pump-turbine model*
}

\author{
De-you $\mathrm{LI}^{1}$, Ru-zhi GONG ${ }^{1}$, Hong-jie WANG ${ }^{\dagger 1}$, Wen-wen $\mathrm{FU}^{1}$, Xian-zhu WEI ${ }^{1,2}$, Zhan-sheng LIU ${ }^{1}$ \\ ( ${ }^{1}$ School of Energy Science and Engineering, Harbin Institute of Technology, Harbin 150001, China) \\ ( ${ }^{2}$ State Key Laboratory of Hydro-Power Equipment, Harbin Institute of Large Electrical Machinery, Harbin 150040, China) \\ †E-mail: wanghongjie@hit.edu.cn
}

Received Apr. 14, 2015; Revision accepted June 30, 2015; Crosschecked Oct. 12, 2015

\begin{abstract}
The energy-discharge characteristics of pump-turbines in pump mode with a hump region are significantly important for operating stability. To investigate the flow characteristics, 3D steady numerical simulations are conducted for a given guide vane opening of $32 \mathrm{~mm}$ by solving Reynolds-averaged Navier-Stokes (RANS) equations using the shear-stress transport (SST) $k$ - $\omega$ turbulence model. Based on the validation of computational fluid dynamics (CFD) results using experimental benchmarks, the part-load $\left(0.45 \varphi_{\mathrm{BEP}}\right)$, drooping zone load $\left(0.65 \varphi_{\mathrm{BEP}}\right)$, near best efficiency point (BEP) $\left(0.90 \varphi_{\mathrm{BEP}}\right), \mathrm{BEP}\left(1.00 \varphi_{\mathrm{BEP}}\right)$, and overload $\left(1.24 \varphi_{\mathrm{BEP}}\right)$ regions are chosen to analyze how and why the fluid properties change in the runner. The causes of flow separation and spatial characteristics of flow at different load points are obtained through the analysis of flow angle and hydraulic losses. The results show that flow angle at the leading and trailing edge from the crown to the band distributes differently among these five operating points. Then, the reasons for drooping are investigated based on the Euler theory. It is found that drooping behavior comes from both the incidence/deviation effect and frictional losses. In addition, the runner losses are more consequential to drooping as shown by hydraulic loss analysis.
\end{abstract}

Key words: Pump-turbine, Flow analysis, Flow angle, Hydraulic loss, Drooping zone doi: 10.1631 jzus.A1500087

Document code: A

CLC number: TK734

\section{Introduction}

According to the International Energy Agency, hydropower is the major renewable electricity generation technology worldwide. Since 2005, hydropower has generated more electricity than all other renewable energies combined (IEA, 2012). Pumped storage power plants develop rapidly due to their effective electricity storage. A pump-turbine is the vital component of a pumped storage power plant.

\footnotetext{
¿ Corresponding author

* Project supported by the National Key Technology R\&D Program of China (No. 2012BAF03B01-X), and the Foundation for Innovative Research Groups of the National Natural Science Foundation of China (No. 51121004)

(17) ORCID: De-you LI, http://orcid.org/0000-0002-3934-1916; Hongjie WANG, http://orcid.org/0000-0003-4775-5016

(C) Zhejiang University and Springer-Verlag Berlin Heidelberg 2015
}

Generally, a pump-turbine is designed for pump mode with consideration for turbine mode. However, the existence of a positive-slope in the energydischarge characteristic curve for a pump-turbine in pump mode will lead to operating instability and limit the operating range to values below the head. Therefore, it is necessary to analyze the energydischarge characteristics of a pump-turbine in pump mode.

Recently, a great deal of research has been carried out to investigate hydraulic performance of pump-turbines in pump and turbine modes. Ran et al. (2011) concluded, based on 3D steady simulation, that the flow pattern near the runner inlet and outlet has important influences on the formation of the hump region. Simulations for small discharge operation conditions of a low specific speed pump-turbine in turbine mode were carried out by Ji and Lai (2011) 
to fit the S-shaped characteristic curve. Compared with the experimental data, it indicates that the S-shaped characteristic has some relationship with the cross flow circle. Wang et al. (2011) conducted internal flow analysis at three typical operating points representing turbine mode, shut-off mode, and reversible pump mode based on experimental and numerical methods. Olimstad et al. (2012) investigated dependency on runner geometry for reversible pump-turbine characteristics in the turbine mode of operation and showed that long-radius leading edges result in less steep characteristics. Anciger et al. (2010) have done some work in predicting the rotating-stall phenomenon and cavitation region. In their research, a more reliable method was developed for prediction of the onset of rotating-stall and an accurate cavitation region. Rotor-stator interaction in pump-turbines in turbine mode was also investigated by Danciocan and Louis (2006), Zobeiri et al. (2006), and Nicolet et al. (2010). Up to now, some 3D unsteady simulations have also been studied using the computational fluid dynamics (CFD) methodology. Backman (2008) and Sun et al. (2012; 2014) predicted the distribution of pressure fluctuations in pump-turbines using 3D unsteady simulations. Hasmatuchi et al. (2010; 2011) and Yan et al. (2012) concluded that one stall cell rotating with the runner with subsynchronous rotating velocity was the main reason of flow separation and flow passages blockage. Similar results were also presented that there exists rotating-stall in the turbine brake operation of pump-turbines by Widmer et al. (2011). Other aspects like misaligned guide vanes (MGV) method and the turbulence model study in pump-turbines were also studied. Xiao et al. (2012) stated that the MGV method in turbine mode could effectively solve S-shaped characteristics, but it still had shortcomings of increasing vibration. Different turbulence models, such as the compressible turbulence model and the improved cavitation model, were adopted to obtain reliable results. Yan et al. (2010) found that numerical results on pressure pulsations induced by rotor-stator interaction (RSI) using compressible turbulence model were closer to the experimental data. Liu et al. (2012) used a compressible improved cavitation model and got a better hump characteristic curve compared with experimental curves. Several different methods of simulation including large eddy simulation (LES), RANS with shear-stress transport
(SST) $k-\omega$ and standard $k-\varepsilon$ turbulence models for simulating a pump-turbine in pump mode were also adopted by Xu et al. (2007), Yin et al. (2011), Li et al. (2013), and Li et al. (2015). However, there has been little research on energy-discharge characteristics. The flow mechanism of a pump-turbine in pump mode is still not clear, especially for the drooping zone. Braun et al. (2005) and Braun (2009) studied unstable energy-discharge characteristics of an industrial pump-turbine in pump mode and concluded that flow patterns, energy and velocity distributions at the rotor-stator interface are related to the onset of recirculation. However, the research just used one channel per component, which could not reflect interaction among the channels. Furthermore, they only carried out the flow analysis in the partload region without addressing in detail the alteration of the characteristic curve in the part load regime, drooping zone load, best efficiency point (BEP) as well as overload regions and the associated flow patterns. Yin et al. (2010) also carried out some similar work to predict the performance and flow pattern of a pump-turbine in pump mode, but this analysis was undertaken just in the vaned distributor at low flow rate. Other cavitation studies related to a pumpturbine in pump mode (Liu et al., 2013; Premkumar et al., 2014) investigated the relation between cavitation and pump mode.

As stated, detailed analysis for different discharge under a given guide vane opening of a pumpturbine in pump mode is not proposed. In this paper, numerical simulations are conducted with a $32 \mathrm{~mm}$ guide vane opening using the SST $k-\omega$ turbulent model. A refined grid is generated to meet the requirements of the chosen turbulence model. Then, how and why the fluid properties change between the part-load, drooping zone load, near BEP, BEP, and overload regions are analyzed based on the validation of CFD results using experimental benchmarks. As for a pump-turbine, the runner is the vital component, so there is detailed analysis in the runner to investigate the causes of flow separation and spatial characteristics of flow at different load points. Furthermore, the reasons for drooping were studied based on the above analysis.

Generally, there are two reasons for drooping deriving from the technical definition. One is Euler or hydraulic rotational momentum of the fluid, which is an input parameter, and the other is the 
frictional losses mostly within the runner space. While the Euler momentum is associated with the shape of the blade (inlet and exit) giving rise to incidence and deviation effects, the losses are determined by both flow separation and boundary layers at different loads. The net head is the resultant of Euler momentum and hydraulic losses, and drooping is the behavior of the two parameters in contrasting ways to cause the head to increase with load instead of decreasing in part-load.

Euler momentum $\left(\Delta c_{\mathrm{u}} \cdot u\right)$ is a function of incidence angle $\left(c_{\mathrm{u} 1}\right)$ at the inlet and deviation angle at the exit $\left(c_{\mathrm{u} 2}\right) .\left(\Delta c_{\mathrm{u}} \cdot u\right)$ can be determined by Eqs. (1) and (2). For experimental methods, Eq. (1) gives an approximate value of Euler torque. However, both Eqs. (1) and (2) can be used while working with the numerical results.

$$
\begin{gathered}
\Delta c_{\mathrm{u}} \cdot u=c_{\mathrm{u} 2} \cdot u_{2}-c_{\mathrm{u} 1} \cdot u_{1}=T \cdot \omega / Q \\
\Delta c_{\mathrm{u}} \cdot u / g=H_{\text {net }}+H_{\text {losses }}
\end{gathered}
$$

where $H$ is the head of the pump-turbine in pump mode, $\mathrm{m} ; H_{\text {net }}$ means the effective head; $H_{\text {losses }}$ means the head caused by hydraulic losses; $T$ denotes hydraulic torque, $\mathrm{N} \cdot \mathrm{m} ; Q$ stands for mass flow rate, $\mathrm{kg} / \mathrm{s} ; \omega$ is the rotational speed of the runner, $\mathrm{rad} / \mathrm{s} ; g$ is acceleration of gravity, $\mathrm{m} / \mathrm{s}^{2} ; u$ is the circumferential velocity, $\mathrm{m} / \mathrm{s} ; c_{\mathrm{u}}$ is circumferential component of absolute velocity, $\mathrm{m} / \mathrm{s}$; and Subscripts 1 and 2 reference to the circumference formed by leading edge and trailing of the blades, respectively.

\section{Numerical modelling}

\subsection{Grid generation}

The pump-turbine model includes the spiral casing, stay-guide vanes, the runner as well as the draft tube. The whole computational domain is created using commercial software NX UG6.0 shown in Fig. 1. Main parameters of the pumpturbine model under investigation are listed in Table 1. The sketch for the pump-turbine model corresponding to the runner outlet diameter $D_{1}$, runner inlet diameter $D_{2}$, and guide vane height $B_{0}$ is shown in Fig. 2.

ANSYS ICEM software is adopted to generate a mesh for each part using structured hexahedral cells shown in Fig. 3. To meet the requirements of the chosen turbulence model (SST $k$ - $\omega$ ), the boundary layer is set with more than 10 nodes off the wall. A non-dimensional wall distance for a wallbounded flow is expressed as $y^{+}$. The $y^{+}$value in wall-adjacent cells of the runner blades, stay vanes, and guide vanes is less than 11 . The spatial average of $y^{+}$for the runner and stay-guide vanes is much less than 6 . One can find that a larger density of nodes is created in the stay-guide vanes and the runner, where near $50 \%$ of the total number of nodes is allocated. The quality of the block structured grid is an aggregative indicator of the mesh orthogonal angle, expansion factor, aspect ratio, and so on. The

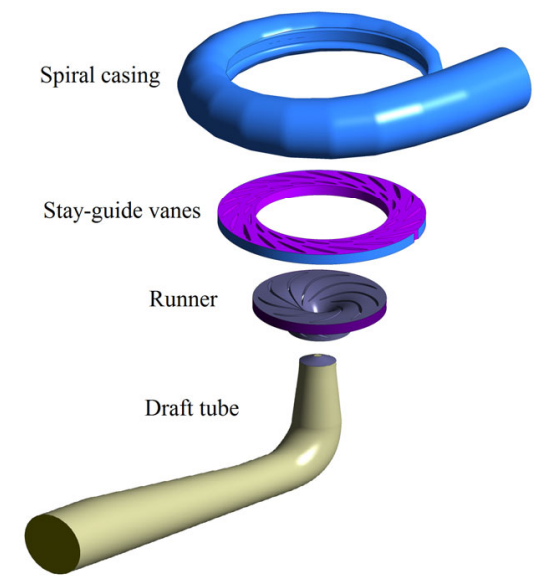

Fig. 1 Computational domain

Table 1 Parameters of pump-turbine model

\begin{tabular}{lc}
\hline \multicolumn{1}{c}{ Parameter } & Value \\
\hline Runner outlet diameter, $D_{1}(\mathrm{~mm})$ & 524 \\
Runner inlet diameter, $D_{2}(\mathrm{~mm})$ & 274 \\
Number of blades, $Z$ & 9 \\
Number of guide vanes, $Z_{\mathrm{G}}$ & 20 \\
Guide vane height, $B_{0}(\mathrm{~mm})$ & 45.77 \\
Number of stay vanes, $Z_{\mathrm{S}}$ & 20 \\
\hline
\end{tabular}

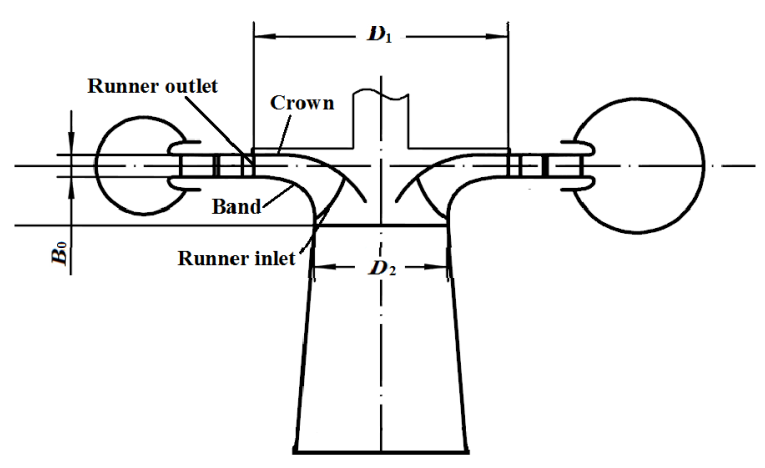

Fig. 2 Sketch of the pump-turbine model 
value of the grid quality ranges from 0 to 1 . A higher value means higher grid quality. The detailed information is listed in Table 2.

(a)

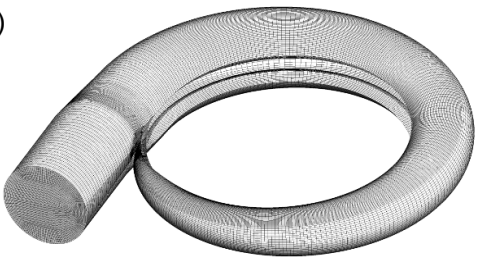

(b)

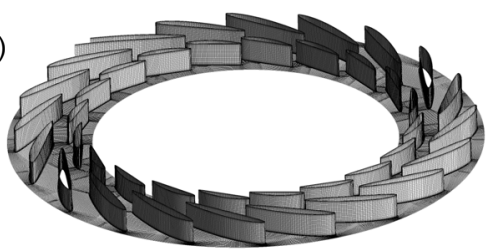

(c)

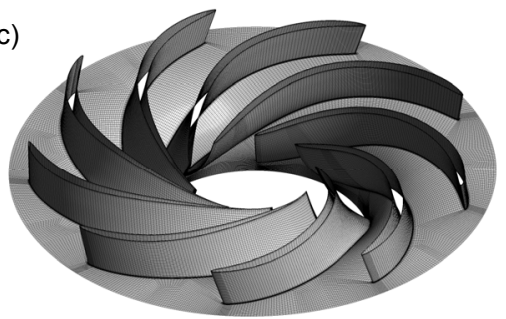

(d)

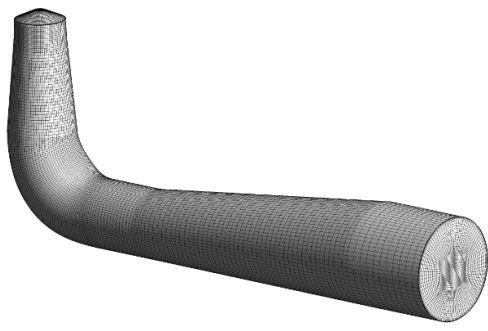

Fig. 3 Grids for different components (a) Spiral casing; (b) Stay-guide vanes; (c) Runner; (d) Draft tube

Table 2 Parameters of the generated grids

\begin{tabular}{lccc}
\hline \multicolumn{1}{c}{ Component } & $\begin{array}{c}\text { Number } \\
\left(\times 10^{6}\right)\end{array}$ & Quality & $y^{+}$average \\
\hline Spiral casing (static) & 0.80 & 0.37 & 707.10 \\
Stay vanes (static) & 0.89 & 0.56 & 1.64 \\
Guide vanes (static) & 1.00 & 0.49 & 1.11 \\
Runner (rotational) & 1.93 & 0.59 & 5.45 \\
Draft tube (static) & 0.84 & 0.61 & 7.37 \\
Total nodes & 5.46 & - & - \\
\hline
\end{tabular}

\subsection{Numerical scheme}

The ANSYS CFX 14.0 commercial code is applied to carry out the steady incompressible turbulent flow numerical simulations. The finite volume method is employed to solve both the incompressible steady-averaged Navier-Stokes equations in their conservative form and the mass conservation equations. The two-equation turbulence model SST $k-\omega$ is used to close the Navier-Stokes equations. Furthermore, a high resolution scheme for all the terms and a convergence criterion $\mathrm{RMS}_{\max }<10^{-6}$ are set. Between rotating and stationary components, a stage average model is used for steady simulations. Simulations are carried out in a microprocessor. The microprocessor is a bi-processor with eight cores Intel Xeon CPU E5-2650 operated at $2.00 \mathrm{GHz}(16$ cores-32 threads in total). The memory cache is $20 \mathrm{MB}$ of L3 and each node processes $64 \mathrm{~GB}$ of DDR3 memory (128 GB in total) operated at $2000 \mathrm{MHz}$.

\subsection{Boundary conditions}

Pressure inlet is used at the draft tube (pump mode). Static pressure $(P=0 \mathrm{~Pa})$ is specified for all cases without consideration of cavitation. The discharge for the spiral casing outlet is imposed and determined by experimental data. No-slip wall conditions in the solid walls are set, and the standard wall function is adopted near the wall. The general grid interface (GGI) is used on the interfaces that separate the rotating and stationary domains, as well as any adjacent domain components.

\section{Experimental validation}

The pump-turbine model is installed in a test rig of the Harbin Institute of Large Electrical Machinery (Fig. 4). Main parameters are listed in Table 3. The test rig allows for both turbine and pump performance assessment within an accuracy of $0.2 \%$, meeting the International Electrotechnical Commission (IEC) standards. $\varphi$ is mass flow coefficient defined as

$$
\varphi=\frac{Q}{\pi R_{1}^{2} \omega}
$$

where $R_{1}$ is runner outlet radius in pump mode, $\mathrm{mm}$.

The optimum guide vane opening of the investigated pump-turbine is $27 \mathrm{~mm}$. The value of $32 \mathrm{~mm}$ is chosen to analyze the flow characteristics. The points at $32 \mathrm{~mm}$ guide vane opening are calculated and shown in Fig. 5. As for energy-discharge curve, 
there is a good correspondence (less than $1.5 \%$ ) in the whole range, with small discrepancies (less than $5 \%$ ) in only the drooping zone and large discharge region. During the drooping zone, the head predicted is less than that from experiments. However, it is overestimated in the large discharge region. Generally, there appears a cavitation phenomenon in the large discharge region, which could not be predicted using the single phase turbulence model. Hence, losses reduced by cavitation could not be estimated. The head predicted shows higher than experiment. As for the drooping zone point, the flow pattern appears extremely unstable, and the prediction accuracy reduces. With respect to efficiency-discharge curve, the maximum error appears in the large discharge region and drooping zone, which is the same with the energy-discharge curve. The Euler headdischarge curve is shown in Fig. 5c, which shows good agreement with the experimental data. It can also be observed that the Euler head decreases with the reducing of the discharge. In addition, the point $0.65 \varphi_{\mathrm{BEP}}\left(\varphi_{\mathrm{BEP}}\right.$ stands for the mass flow coefficient of the BEP) shows a slight decline in the Euler headdischarge curve shown in Fig. 5c, and a hump region $\left(0.65 \varphi_{\mathrm{BEP}}\right)$ in the net head-discharge curve could be observed. Hence, the point $0.65 \varphi_{\mathrm{BEP}}$ is validated as the drooping load coming from the hydraulic

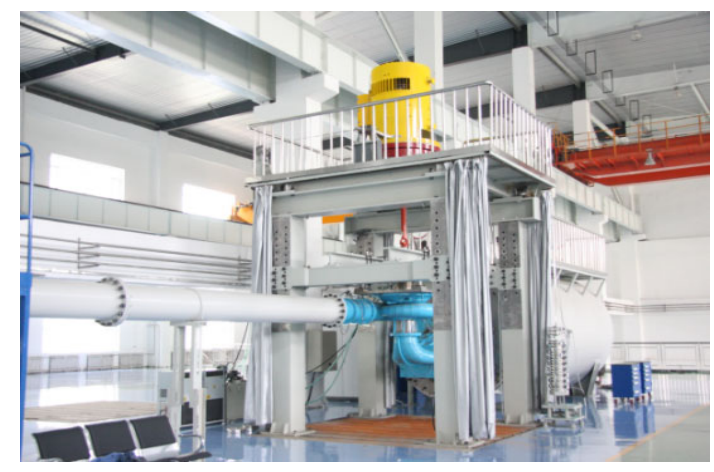

Fig. 4 Test rig of a pump-turbine model

Table 3 Parameters of the test rig

\begin{tabular}{lc}
\hline \multicolumn{1}{c}{ Characteristic } & Value \\
\hline Maximum head $(\mathrm{m})$ & 80 \\
Maximum discharge $\left(\mathrm{m}^{3} / \mathrm{s}\right)$ & 0.8 \\
Impeller diameter range $(\mathrm{mm})$ & $300-500$ \\
Generating power $(\mathrm{kW})$ & 750 \\
Test rig accuracy for all parameters $(\%)$ & \pm 0.20 \\
\hline
\end{tabular}

rotational momentum of the fluid and frictional losses. In sum, external characteristic curves show satisfactory agreement with the experimental data. In addition, the experimental behavior of the pumpturbine in pump mode, determined on a professional and well-calibrated test rig, is quite stable in the part load zone and does not display any adverse instability of drooping. Further study can be carried out based on the validation.
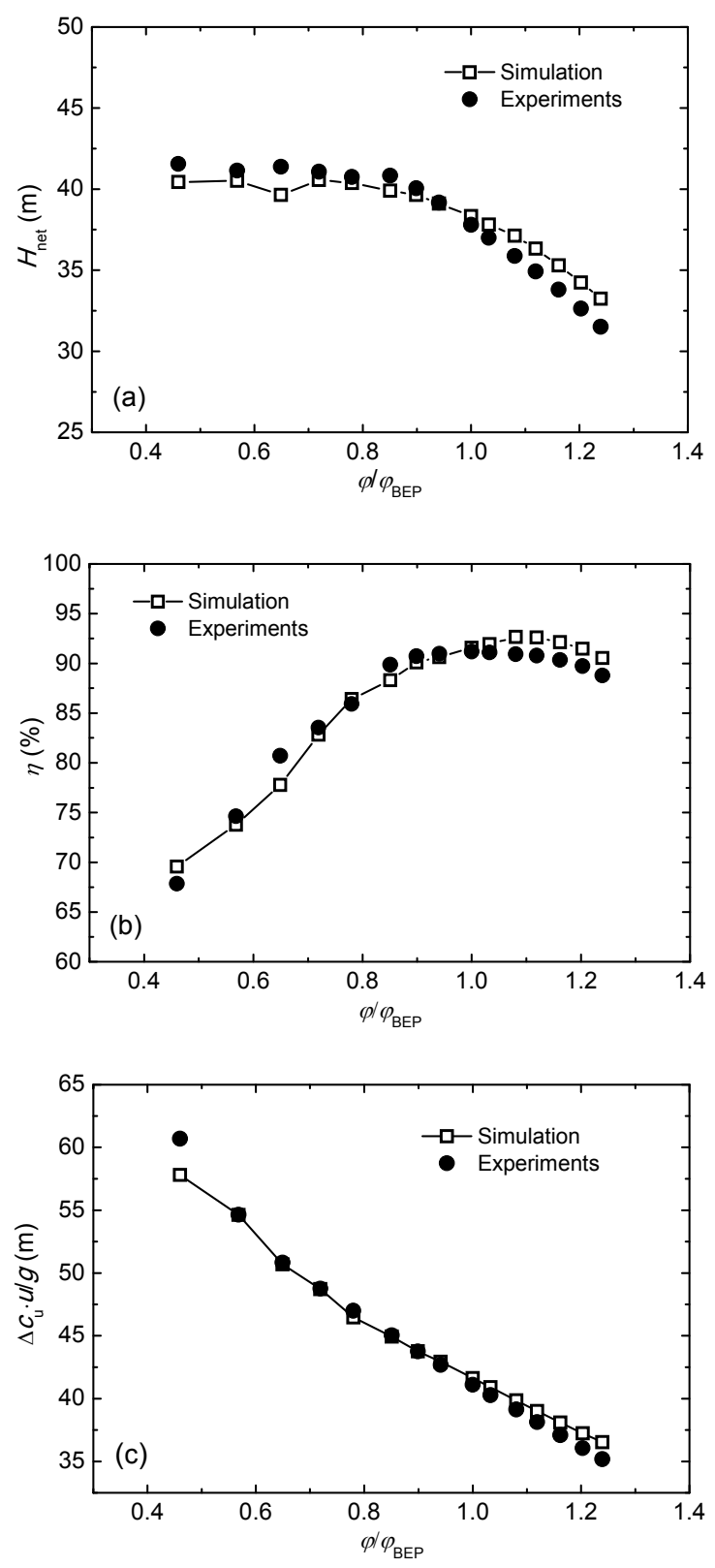

Fig. 5 External characteristics curves

(a) Energy-discharge curve; (b) Efficiency-discharge curve;

(c) Euler head-discharge curve 


\section{Numerical analysis}

From the external characteristic curve, five points, i.e., part-load $\left(0.45 \varphi_{\mathrm{BEP}}\right)$, drooping zone load $\left(0.65 \varphi_{\mathrm{BEP}}\right)$, near $\operatorname{BEP}\left(0.90 \varphi_{\mathrm{BEP}}\right)$, BEP $\left(1.00 \varphi_{\mathrm{BEP}}\right)$, and overload $\left(1.24 \varphi_{\mathrm{BEP}}\right)$, shown in Fig. 6 are chosen to analyze how and why the fluid properties change, where $H_{\text {net }}{ }^{\mathrm{BEP}}$ is the effective head at BEP.

\subsection{Analysis of flow angle}

The specific notations used in flow field analysis are given in Fig. 7. Blade-to-blade locations from the crown to the band are defined from 0 to 1 in the spanwise direction. Two cross-sections (streamwise 1 and streamwise 2) are defined in the runner inlet and runner outlet (pump mode) in the streamwise direction, respectively. Four flow planes A $(0.2,1.20)$ (means spanwise 0.2 , streamwise 1.20$), \mathrm{B}(0.5,1.15)$, $\mathrm{C}(0.8,1.09)$, and $\mathrm{D}(0.95,1.13)$ are chosen to analyze flow characteristics. The sketch of the blade to blade section is shown in Fig. 8. Rotational direction, trailing edge, leading edge, pressure surface, and suction surface can be found in Fig. 8 .

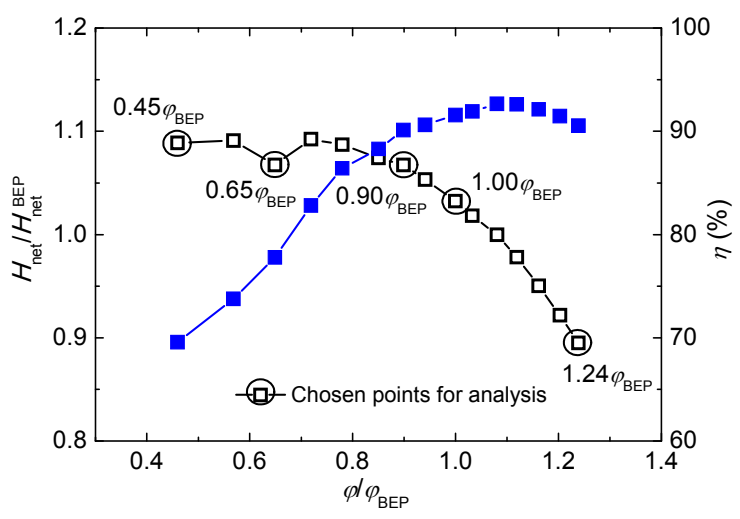

Fig. 6 Information of the chosen analysis points

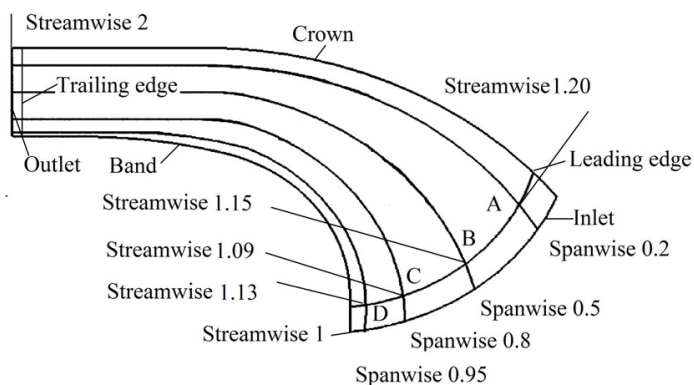

Fig. 7 Schematic diagram of cross-sections studied

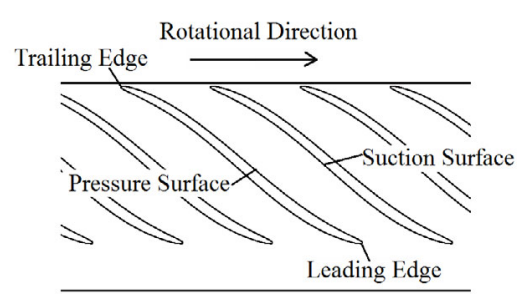

Fig. 8 Sketch of blade to blade section

\subsubsection{Inlet flow angle}

The flow angle distribution at the leading edge in different spanwise directions for different operating conditions at the $32 \mathrm{~mm}$ guide vane opening is shown in Fig. 9. Flow angle is the angle of absolute velocity and circumferential velocity of the flow. The variation of flow angle at the leading edge from the crown to the band is shown in Fig. 9a. $\theta$ ranges from $0^{\circ}$ to $360^{\circ}$ according to rotational direction. It has an upward trend from spanwise 0 to spanwise 0.2 . Then, it experiences a decline until spanwise 0.8. As for BEP $\left(1.00 \varphi_{\mathrm{BEP}}\right)$ and near BEP $\left(0.90 \varphi_{\mathrm{BEP}}\right)$, the tendency of flow angle is almost the same and flow angle decreases slightly. As for the point $0.45 \varphi_{\mathrm{BEP}}$, the flow angle increases from spanwise 0.85 . Its value exceeds $90^{\circ}$ when it reaches spanwise 0.92 . With respect to drooping zone point $0.65 \varphi_{\mathrm{BEP}}$, it decreases significantly from spanwise 0.97 , and its value is below $0^{\circ}$. For the overload $1.24 \varphi_{\mathrm{BEP}}$ operating point, the flow angle also has an obvious increase from spanwise 0.8 . The area in which the flow angle is over $90^{\circ}$ or below $0^{\circ}$ indicates that there appears to be serious backflow. The value of $c_{\mathrm{u} 1} \cdot u_{1}$ decreases as the increase of flow angle $\left(0^{\circ}-180^{\circ}\right)$. However, it increases for drooping zone point $0.65 \varphi_{\mathrm{BEP}}$ due to the reduction of the flow angle.

Most of the operating points feature periodic distribution. In each runner passage, the flow angle at the leading edge decreases first, then increases from the pressure surface to the suction surface of blades. With the decrease of the discharge, the flow angle shows a decline, and the rate of decrease increases from the crown to the band.

With respect to the point in the drooping zone, the distribution of the flow angle features disorder, which is obviously different from other operating points. In addition, the flow angle in several passages reaches the smallest among these five points. It 

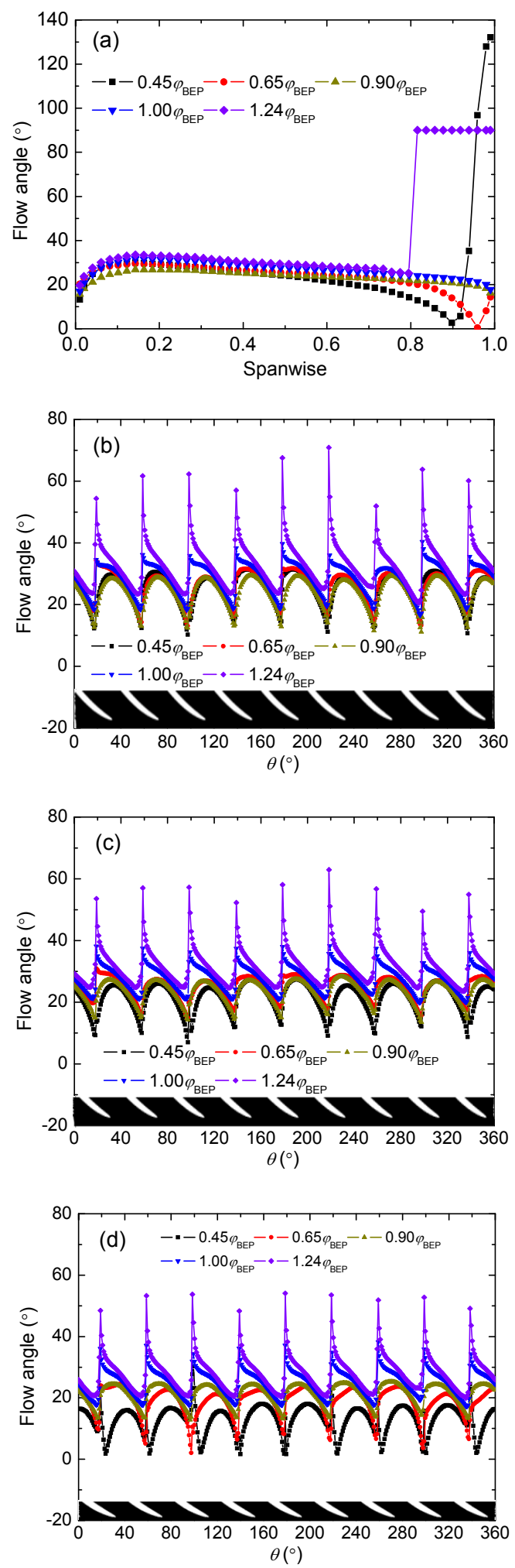

Fig. 9 Flow angle of leading edge with different operating points

(a) Flow angle from crown to band; (b) Spanwise 0.2, streamwise 1.20; (c) Spanwise 0.5, streamwise 1.15; (d) Spanwise 0.8, streamwise 1.09 leads to $c_{\mathrm{u} 1} \cdot u_{1}$ increasing. In the drooping zone region, the flow field is complex and the streamline distribution in each runner passage is different. The value of the flow angle for the overload point $\left(1.24 \varphi_{\mathrm{BEP}}\right)$ is the highest among these five operating points. The variation range is also the highest. The maximum exceed $60^{\circ}$. The difference between the maximum and the minimum reaches $40^{\circ}$. As for $\operatorname{BEP}\left(1.00 \varphi_{\mathrm{BEP}}\right)$ and near BEP $\left(0.90 \varphi_{\mathrm{BEP}}\right)$, the flow angle variation is small. The value is mostly around $25^{\circ}$. From the crown to the band, the value changes slightly. Furthermore, the efficiency for these two points is high as shown in Fig. 6. A slight variation of flow angle at the leading edge could reduce the flow separation in the runner passage. There is an obvious difference for the part-load point $\left(0.45 \varphi_{\mathrm{BEP}}\right)$, where the minimum is near $0^{\circ}$.

The variation from the crown to the band is significantly large. Moreover, the flow angle shows a good periodicity. It can be concluded that, for the point in the droop zone at the leading edge, the flow field shows complexity, and the distribution of the flow angle is disordered, unlike the other four operating points.

Flow angle comparison of condition points $0.45 \varphi_{\mathrm{BEP}}$ and $0.65 \varphi_{\mathrm{BEP}}$ in the plane $\mathrm{D}(0.95,1.13)$ is shown in Fig. 10. There appear to be backflow regions. As for point $0.65 \varphi_{\mathrm{BEP}}$ in the plane close to the band, two backflow regions (flow angle over $90^{\circ}$ ) can be observed. However, five backflow regions can be found for point $0.45 \varphi_{\mathrm{BEP}}$. It illustrates that the phenomenon of backflow will not appear in the runner passages at the same time, but will appear in several passages first, then will spread to all passages with the decrease of the discharge.

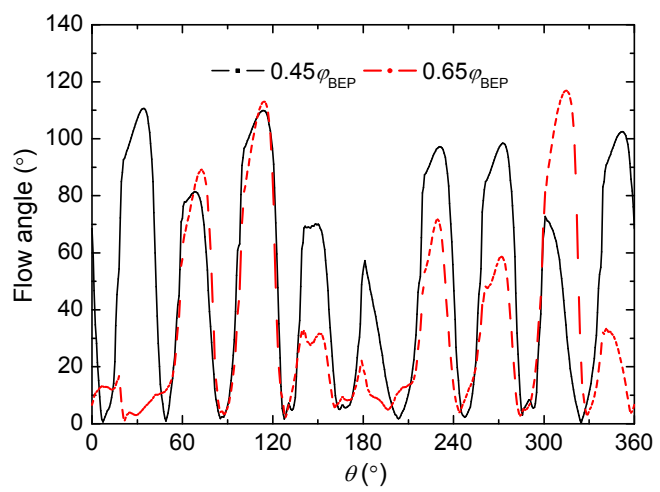

Fig. 10 Flow angle distribution at $0.45 \varphi_{\mathrm{BEP}}$ and $0.65 \varphi_{\mathrm{BEP}}$ operating condition $(0.95,1.13)$ 
Fig. 11 shows the flow field changes with the decrease of the discharge at plane $\mathrm{D}(0.95,1.13)$ near the band. The positive direction of attack angle changes to negative from the overload point to the part-load point. As for the overload point $\left(1.24 \varphi_{\mathrm{BEP}}\right)$, $\operatorname{BEP}\left(1.00 \varphi_{\mathrm{BEP}}\right)$, and near BEP $\left(0.90 \varphi_{\mathrm{BEP}}\right)$, no obvious flow separation can be observed at the leading edge on the suction surface. The hydraulic loss is small and therefore the efficiency is high.
However, with respect to drooping zone point $\left(0.65 \varphi_{\mathrm{BEP}}\right)$ and part-load point $\left(0.45 \varphi_{\mathrm{BEP}}\right)$, the separation and backflow can be found in the runner passage inlet. Separation mainly appears at the suction surface of the blade, while backflow occurs near the pressure surface in the runner passage inlet.

\subsubsection{Exit flow angle}

The angle distribution at the trailing edge is shown in Fig. 12. From the crown to the band shown

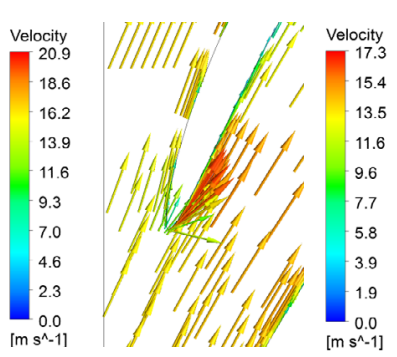

Overload $\left(1.24 \varphi_{\mathrm{BEP}}\right)$

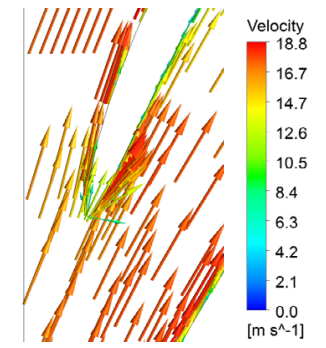

$\mathrm{BEP}$

$\left(\varphi_{\mathrm{BEP}}\right)$
Near BEP
$\left(0.90 \varphi_{\mathrm{BEP}}\right)$

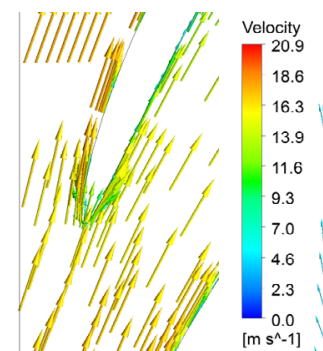

Drooping zone load

$\left(0.65 \varphi_{\mathrm{BEP}}\right)$

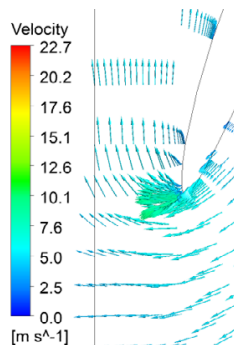

Part load

$\left(0.45 \varphi_{\mathrm{BEP}}\right)$

Fig. 11 Process of backflow at the leading edge of the blade $(0.95,1.13)$
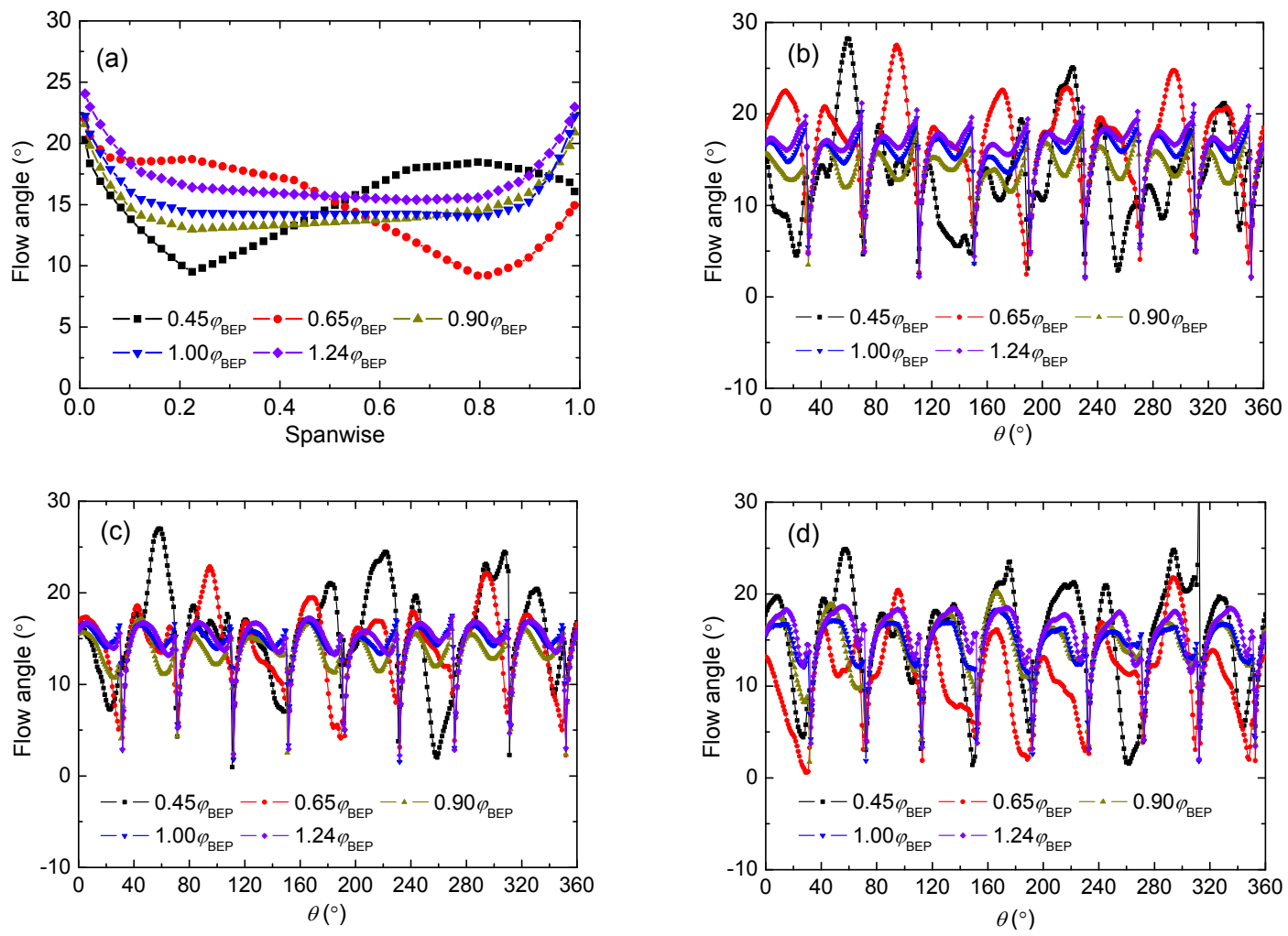

Fig. 12 Flow angle of trailing edge with different operating points

(a) Flow angle from crown to band; (b) Spanwise 0.2, streamwise 1.97; (c) Spanwise 0.5, streamwise 1.97; (d) Spanwise 0.8, streawise 1.97 
in Fig. 11d, the trend of the flow angle around the BEP is nearly the same. The value decreases at first, and then increases. The flow angle decreases with the reduction of the discharge. Hence, the value of $c_{\mathrm{u} 2} \cdot u_{2}$ increases as the discharge is reduced. However, as for the part-load point and the drooping zone point, the trend of the flow angle is not same with the other three points. Only half of the flow angle in the spanwise direction is lower than those of other three points. In addition, with respect to the part-load point, the minimum appears near the spanwise 0.2 , while it occurs in spanwise 0.8 for the drooping zone point. Hence, $c_{\mathrm{u} 1} \cdot u_{1}$ increases for these two low discharge points. The distribution of the flow angle in the circumferential direction for different spanwise is represented in Figs. 12a-12c. There is an obvious periodicity for the overload point $\left(1.24 \varphi_{\mathrm{BEP}}\right)$, BEP $\left(1.00 \varphi_{\mathrm{BEP}}\right)$, and near BEP $\left(0.90 \varphi_{\mathrm{BEP}}\right)$ in the different spanwise directions. The variation of flow angle distribution in spanwise 0.5 around BEP is almost the same. In spanwise 0.2 , the value decreases with the reduction of the discharge. However, it is different in spanwise 0.8 . For the drooping zone point $\left(0.65 \varphi_{\mathrm{BEP}}\right)$ and the part-load point $\left(0.45 \varphi_{\mathrm{BEP}}\right)$, the flow angle distribution appears disordered, and the variation range is large. At the trailing edge in the runner outlet, the flow field is complex. The angle of attack for guide vanes will be larger for these two points, and it will be easier to generate flow separation. It will lead to big losses in the tandem cascade.

Based on the analysis of inlet and exit angles around the BEP, $c_{\mathrm{u} 2} \cdot u_{2}$ increases due to the decrease of flow angle as the discharge is reduced, and $c_{\mathrm{ul}} \cdot u_{1}$ deceases due to the increase of flow angle with the reduction of the discharge. It shows the Euler head increase (Fig. 5c) as the discharge increases at a fixed speed. However, with respect to drooping zone point $\left(0.65 \varphi_{\mathrm{BEP}}\right), c_{\mathrm{u} 2} \cdot u_{2}$ decreases due to the increase of the flow angle in some positions, and $c_{\mathrm{u} 1} \cdot u_{1}$ increases due to the decrease of the flow angle over spanwise 0.97. It leads to a slight decline in the Euler head-discharge curve shown in Fig. 5c.

\subsection{Flow field analysis}

From the above, changes of the flow angle have an evident influence on the flow in the runner passage. It is the combined effect of the axial vortex due to the inertial effect and cross flow in the steady run- ner that contribute to the complex flow condition in the runner passage. The flow vector distribution in the runner is shown in Fig. 13. Among the five operating points, the maximum velocity is the smallest for BEP. As the discharge is reduced or increased, the maximum velocity increases. The direction of attack angle at the leading edge changes as the reduction of the discharge. As for the drooping zone point and the part-load point, obvious flow separation can be observed on the suction surface. In sum, around the BEP the flow field is smooth, and the distribution accords with the theoretical distribution law. However, with the decrease of the discharge, two phenomena will appear: (1) flow separation will happen at the suction surface of blades; (2) the flow rate within runner passages gradually decreases. Because of the influence of the two factors mentioned, the fluid near the suction surface at the band in the runner inlet cannot overcome the viscous force and the increase of the pressure in the flow direction (Fig. 14). Therefore, flow separation appears in this region, and then generates a separation vortex. The separation vortex will disorder the runner inlet flow field and change the runner inlet flow angle. The influence range will increase with the decrease of the discharge and spread to the crown along the flow direction. This analysis is the same with the inlet flow angle variation.

From Fig. 14, for BEP, the gradient of the pressure distribution is the smallest. No obvious mutation could be found in the figure. The maximum of the pressure increases from large discharge points to small discharge points. Combining the flow vector, backflow near the band could be observed.

Furthermore, the backflow near the band in the inlet leads to decrease of the inlet flow area of passages and increase of the flow drag force, which lowers the through-flow capacity. On the other hand, the discharge near the crown increases as the fluid is blocked near the band, which has a beneficial effect with the flow field near the crown. Furthermore, the flow angle near the crown does not deviate much compared with BEP.

\subsection{Hydraulic loss analysis}

Frictional losses of the pump-turbine are presented in Fig. 15 (p.861). Overall, the numerical results have good agreement with experiment. It 
(a)

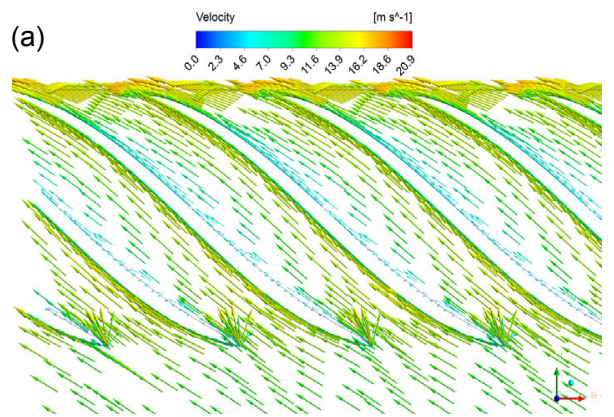

(b)

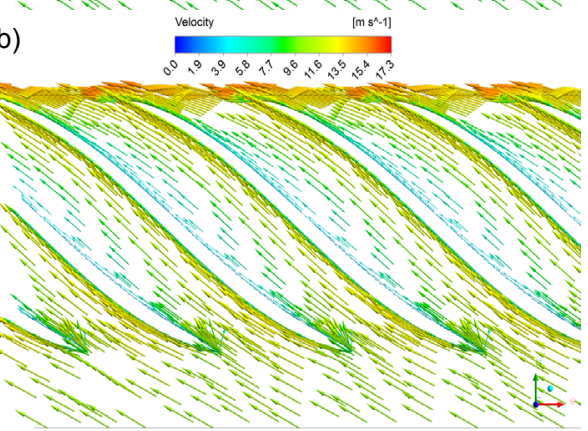

(c)
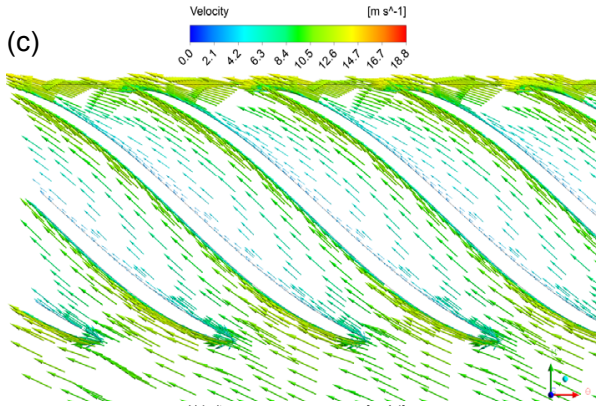

(d)

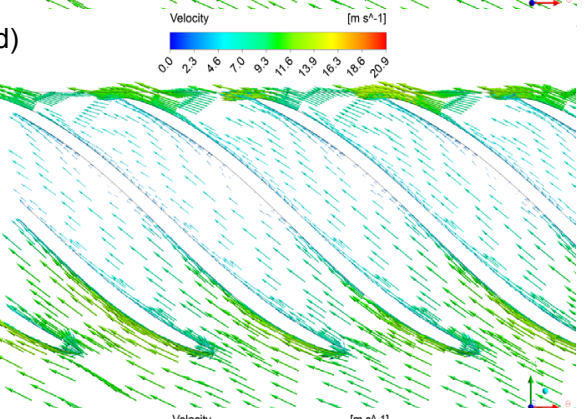

(e)

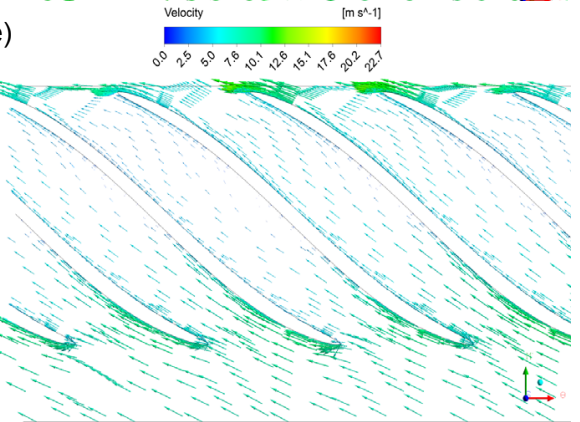

Fig. 13 Flow vector distribution (spanwise 0.5)

(a) Overload $\left(1.24 \varphi_{\mathrm{BEP}}\right)$; (b) BEP $\left(1.00 \varphi_{\mathrm{BEP}}\right)$; (c) Near BEP $\left(0.90 \varphi_{\mathrm{BEP}}\right)$; (d) Drooping zone load $\left(0.65 \varphi_{\mathrm{BEP}}\right)$; (e) Part load $\left(0.45 \varphi_{\mathrm{BEP}}\right)$
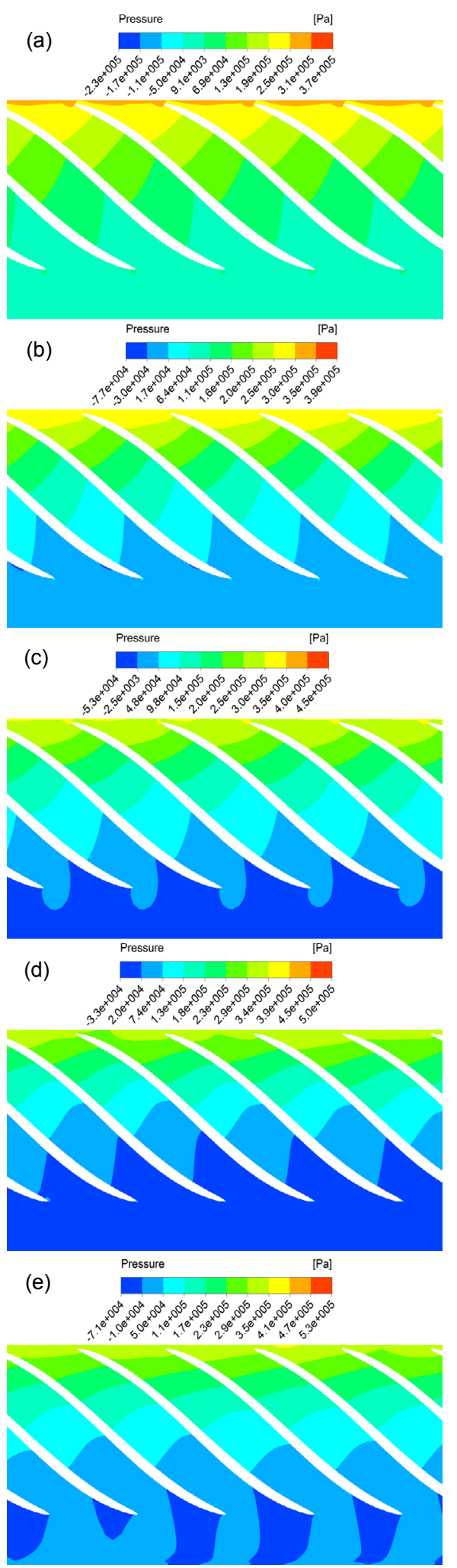

Fig. 14 Pressure distribution (spanwise 0.5) (a) Overload $\left(1.24 \varphi_{\mathrm{BEP}}\right)$; (b) BEP $\left(1.00 \varphi_{\mathrm{BEP}}\right)$; (c) Near BEP $\left(0.90 \varphi_{\mathrm{BEP}}\right)$; (d) Drooping zone load $\left(0.65 \varphi_{\mathrm{BEP}}\right)$; (e) Part load $\left(0.45 \varphi_{\mathrm{BEP}}\right)$ 


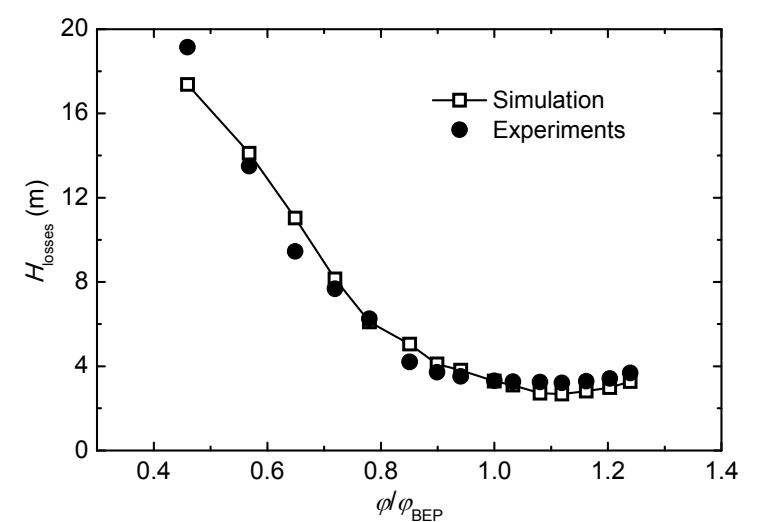

Fig. 15 Frictional losses of the pump-turbine

illustrates that the frictional losses at BEP are the lowest, and sharply increase with the decrease of the discharge. At the drooping zone point $\left(0.65 \varphi_{\mathrm{BEP}}\right)$, the losses show a small upward trend in the simulation line. The drooping phenomenon is also related to frictional losses.

To analyze the loss for runner and tandem cascade, A-A, B-B, and C-C sections shown in Fig. 16 are chosen. In pump mode, fluid energy comes from the rotational runner, so the calculation expression is that runner losses are equal to runner input energy plus the energy difference between the runner inlet and outlet, while the losses of tandem cascade are the drop of total pressure.

Variation of hydraulic losses is shown in Fig. 17. Around the best efficiency point, the runner losses and tandem losses are at a minimum. As the discharge decreases to the conditions when backflow and flow separation are observed, the losses for runner and tandem increase sharply. However, the small discharge condition is more adaptive to the small discharge operating condition, which can decrease the runner losses. The largest hydraulic loss in the runner is in the drooping zone, which makes the head drop in the energy-discharge curve. As for the overload point, BEP and near BEP, no obvious flow separation could be observed in the runner passage. Hence, the hydraulic loss shows as very small as shown in Fig. 17. Combining to Figs. 15 and 16, hydraulic losses mainly come from the runner and tandem cascade. Due to the increase of the flow angle, the angle of attack for guide vanes increases, which is easier for the generation of flow separation in the tandem cascade. Hence, the losses in the tan- dem cascade increase sharply as shown in Fig. 17. It can be concluded that the runner losses are more in consequence of drooping.

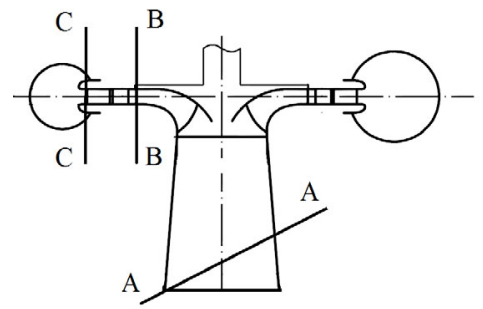

Fig. 16 Schematic diagram of cross plane outlet

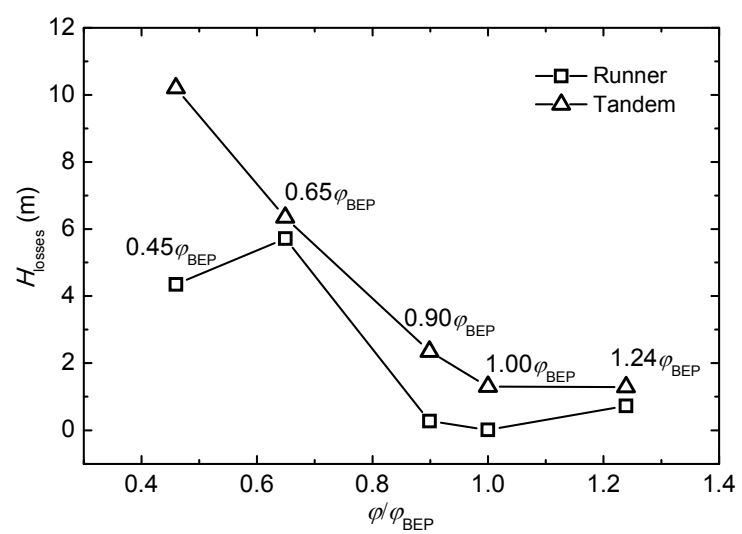

Fig. 17 Variation of hydraulic loss

\section{Conclusions}

In this paper, 3D numerical simulations at $32 \mathrm{~mm}$ guide vane opening are carried out to investigate the energy-discharge characteristics of a pump-turbine model in pump mode using the SST $k$ $\omega$ turbulence model. Based on validation of CFD results using experimental benchmarks, the part-load $\left(0.45 \varphi_{\mathrm{BEP}}\right)$, drooping zone load $\left(0.65 \varphi_{\mathrm{BEP}}\right)$, near BEP $\left(0.90 \varphi_{\mathrm{BEP}}\right), \mathrm{BEP}\left(1.00 \varphi_{\mathrm{BEP}}\right)$, and overload $\left(1.24 \varphi_{\mathrm{BEP}}\right)$ regions are chosen to analyze the change of flow characteristics, especially for the drooping zone. It can be concluded that drooping behavior is coming from both the incidence/deviation $\left(\Delta c_{\mathrm{u}} \cdot u\right)$ effect and frictional losses. Hydraulic losses mainly focus on the runner and tandem cascade. Furthermore, the runner losses are more consequential to drooping. To avoid the drooping instability zone, the shape of the blades should be optimized to reduce giving rise to incidence and deviation effects. 
In this paper, the drooping is investigated for a given guide vane setting. A study comprising the influence of guide vane setting on the drooping performance should be studied in the future. It will depend on the influence of exit flow angle on the drooping head, because downstream geometric conditions could affect the exit flow angle, in turn making guide setting a variable. The study could contribute effectively not only to a reversible pump turbine in a pumped storage power plant, but also a pump in the turbomachinery systems.

\section{References}

Anciger, D., Jung, A., Aschenbrenner, T., 2010. Prediction of rotating stall and cavitation inception in pump turbines. IOP Conference Series: Earth and Environmental Science, 12(1):012013. [doi:10.1088/1755-1315/12/1/ 012013]

Backman, G., 2008. CFD validation of pressure fluctuations in a pump-turbine. Master Thesis, Lulea University of technology, Lulea, Sweden.

Braun, O., 2009. Part Load Flow in Radial Centrifugal Pumps. $\mathrm{PhD}$ Thesis, Ecole Polytechnique Federale de Lausanne, Switzerland.

Braun, O., Kueny, J.L., Avellan, F., 2005. Numerical analysis of flow phenomena related to the unstable energydischarge characteristic of a pump-turbine in pump mode. ASME Fluids Engineering Division Summer Meeting, Houston, USA.

Danciocan, G., Louis, J., 2006. Experimental analysis of rotor-stator interaction in a pump-turbine. Proceedings of 23rd IAHR Symposium, Yokohama, Japan.

Hasmatuchi, V., Roth, S., Botero, F., et al., 2010. High-speed flow visualization in a pump-turbine under off-design operating conditions. IOP Conference Series: Earth and Environmental Science, 12:012059. [doi:10.1088/17551315/12/1/012059]

Hasmatuchi, V., Roth, S., Botero, F., et al., 2011. Hydrodynamics of a pump-turbine at off-design operating conditions: numerical simulation. ASME-JSME-KSME Joint Fluids Engineering Conference, American Society of Mechanical Engineers, p.495-506.

International Energy Agency (IEA), 2012. Technology Roadmap: Hydropower. Technical Report, IEA, Paris, France. Available from: http://www.iea.org/publications/ freepublications/publication/technology-roadmap-hydro power.html [Accessed on Apr. 14, 2014].

Ji, X.Y., Lai, X., 2011. Numerical simulation of the S-shape characteristics of the pump-turbine. Chinese Journal of Hydrodynamics, 26(3):318-325 (in Chinese).

Li, D.Y., Wang, H.J., Xiang, G.M., et al., 2015. Unsteady simulation and analysis for hump characteristics of a pump turbine model. Renewable Energy, 77:32-42. [doi:10.1016/j.renene.2014.12.004]
Li, W., Qian, Z.D., Gao, Y.Y., 2013. Comparison of pressure oscillation characteristics in a Francis hydraulic turbine with four different turbulence models. Engineering Journal of Wuhan University, 46(2):174-179 (in Chinese).

Liu, J.T., Liu, S.H., Wu, Y.L., et al., 2012. Numerical investigation of the hump characteristic of a pump-turbine based on an improved cavitation model. Computers \& Fluids, 68:105-111. [doi:10.1016/j.compfluid.2012.08. 001]

Liu, J.T., Wu, Y.L., Liu, S.H., 2013. Study of unsteady cavitation flow of a pump-turbine at pump mode. IOP Conference Series: Materials Science and Engineering, 52: 062021. [doi:10.1088/1757-899X/52/6/062021]

Nicolet, C., Ruchonner, N., Alligne, S., et al., 2010. Hydroacoustic simulation of rotor-stator interaction in resonance conditions in Francis pump-turbine. IOP Conference Series: Earth and Environmental Science, 12:012005. [doi:10.1088/1755-1315/12/1/012005]

Olimstad, G., Nielsen, T., Børresen, B., 2012. Dependency on runner geometry for reversible pump turbine characteristics in turbine mode of operation. Journal of Fluids Engineering, 134(12):121102. [doi:10.1115/1.4007897]

Premkumar, T.M., Kumar, P., Chatterjee, D., 2014. Cavitation characteristics of S-blade used in fully reversible pump-turbine. Journal of Fluids Engineering, 136(5): 051101. [doi:10.1115/1.4026441]

Ran, H.J., Zhang, Y., Luo, X.W., et al., 2011. Numerical simulation of the positive-slope performance curve of reversible hydro-turbine in pumping mode. Journal of Hydroelectric Engineering, 30(3):175-179 (in Chinese).

Sun, Y.K., Zuo, Z.G., Liu, S.H., 2012. Numerical study of pressure fluctuations in different guide vanes' opening angle in pump mode of a pump-turbine. IOP Conference Series: Earth and Environmental Science, 15:062037. [doi:10.1088/1755-1315/15/6/062037]

Sun, Y.K., Zuo, Z.G., Liu, S.H., et al., 2014. Distribution of pressure fluctuations in a prototype pump turbine at pump mode. Advances in Mechanical Engineering, 6: 923937. [doi:10.1155/2014/923937]

Wang, L.Q., Yin, J.L., Jiao, L., et al., 2011. Numerical investigation in the "S" characteristics of a reduced pump turbine model. Science China Technological Sciences, 54(5):1259-1266. [doi:10.1007/s11431-011-4295-2]

Widmer, C., Staubli, T., Ledergerber, N., 2011. Unstable characteristic and rotating stall in turbine brake operation of pump-turbines. Journal of Fluids Engineering, 133(4): 041101. [doi:10.1115/1.4003874]

Xiao, R.F., Sun, H., Liu, W.C., et al., 2012. Analysis of S characteristics and its pressure pulsation of pump-turbine under pre-opening guide vanes. Journal of Mechanical Engineering, 48(08):174-179. [doi:10.3901/JME.2012. 08.174]

Xu, L., Cui, G.X., Xu, C.X., et al., 2007. Large eddy simulation of flows passage of reversible runner. Journal of Hydroelectric Engineering, 26(4):124-129.

Yan, J., Koutnik, J., Seidel, U., 2010. Compressible 
simulation of rotor-stator interaction in pump-turbines. IOP Conference Series: Earth and Environmental Science, 12: 012008. [doi:10.1088/1755-1315/12/1/012008]

Yan, J., Seidel, U., Koutnik, J., 2012. Numerical simulation of hydrodynamics in a pump-turbine at off-design operating conditions in turbine mode. IOP Conference Series. Earth and Environmental Science, 15:032041. [doi:10. 1088/1755-1315/15/3/032041]

Yin, J.L., Liu, J.T., Wang, L.Q., 2010. Performance prediction and flow analysis in the vaned distributor of a pump-turbine under low flow rate in pump mode. Science China Technological Sciences, 53(12):3302-3309. [doi:10.1007/s11431-010-4175-1]

Yin, J.L., Liu, J.T., Wang, L.Q., et al., 2011. Prediction of pressure fluctuations of pump-turbine under off-design condition in pump-turbine. Journal of Engineering Thermophysics, 32(07):1141-1144.

Zobeiri, A., Kueny, J.L., Farhat, M., 2006. Pump-turbine rotor-stator interactions in generating mode: pressure fluctuation in distributor channel. 23rd IAHR Symposium on Hydraulic Machinery and Systems, Yokohama, Japan.

\section{中文概要}

题 目: 给定活动导叶开口水洜水轮机模型原工况驼峰 现象流动分析
目的：探索水百水轮机泵工况在超负荷工况 $\left(1.24 \varphi_{\mathrm{BEP}}\right)$ 、最优工况 $\left(1.00 \varphi_{\mathrm{BEP}}\right)$ 、靠近最优 工况 $\left(0.90 \varphi_{\mathrm{BEP}}\right)$ 、驼峰区工况 $\left(0.65 \varphi_{\mathrm{BEP}}\right)$ 以及 低负荷工况 $\left(0.45 \varphi_{\mathrm{BEP}}\right)$ 的流动特性, 期望获得 流动特性变化规律, 揭示驼峰特性形成机理。

方 法: 对某一水泵水轮机模型, 采用剪切压力传输 (SST) $k-\omega$ 湍流模型进行三维定常数值模拟, 在 实验验证的基础上: 1. 在曲面坐标系中, 分析 由叶片形状所引起的各个工况叶片进出口边在 周向和叶片方向上的分布规律; 2. 运用经典欧 拉理论分析叶片进出口边液流角变化对各个工 况的欧拉水头的影响; 3 . 通过水力损失分析, 获得不同部件各个工况损失变化规律。

结 论: 1. 转轮叶片进出水边的液流角随着叶片方向在 不同流量工况分布下具有明显差异, 导致转轮 流道不同程度流动分离; 2. 运用经典欧拉理论 得出驼峰区工况点出口角液流的减小与入口液 流的增加是驼峰特性产生的主要原因之一; 3. 通过损失分析, 确定百工况损失主要在转轮 和双列叶栅中, 得出转轮部分损失是驼峰特性 形成的主要原因之一; 4. 综合分析, 驼峰特性 是由该工况欧拉动量的减小和转轮部分损失的 增加共同作用的结果。

关键词: 水洜水轮机; 流动分析; 液流角; 水力损失; 驼峰区 